\title{
Editorial
}

\section{Looking at Things in New Ways}

\author{
Denise Koufogiannakis \\ Editor-in-Chief \\ Collections \& Acquisitions Coordinator, University of Alberta Libraries \\ Edmonton, Alberta, Canada \\ Email: denise.koufogiannakis@ualberta.ca
}

\begin{abstract}
Q 2010 Koufogiannakis. This is an Open Access article distributed under the terms of the Creative CommonsAttribution-Noncommercial-Share Alike License 2.5 Canada (http://creativecommons.org/licenses/by-nc-

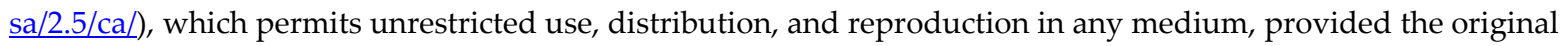
work is properly attributed, not used for commercial purposes, and, if transformed, the resulting work is redistributed under the same or similar license to this one.
\end{abstract}

Welcome to the first issue of our $5^{\text {th }}$ volume of Evidence Based Library and Information Practice. And what an issue it is! We are very pleased to showcase the keynote addresses from the $5^{\text {th }}$ International Evidence Based Library and Information Practice (EBLIP5) conference that took place in Stockholm, Sweden in July 2009. Andrew Booth, who was Chair of the International Program Committee for the conference, kindly agreed to take on a guest editorial role in gathering these keynote presentations together. I believe it is the first time the EBLIP community has been able to have the keynote papers from an EBLIP conference gathered in this way. Reading these commentaries will give you a true sense of the themes and questions that were woven throughout the conference and will give you lots to think about. For a fuller description and to put this Feature section in context, please be sure to read Andrew's editorial at the beginning of the section.

As we begin our fifth year of publication, submissions of original research articles continue to grow. In this issue we have five original articles on topics ranging from information literacy instruction to cataloguing of e-books. Two articles look at using communities of practice in the support of evidence based practice; clearly this is an area of emerging research within EBLIP that readers will benefit from learning more about. One of these articles, by Urquhart, Brice, Cooper, Spink, and Thomas, won the Best Oral Presentation award at the EBLIP5 conference.

In addition to the original research articles, we also have seven evidence summaries, covering topics such as unionization, information seeking behaviour, and the LIS blogosphere. The EBL101 column tackles critical appraisal, a daunting task that will not seem quite so scary once you've read the column! As well, in the Commentary section, Jessie McGowan and colleagues have contributed a checklist for the peer review of electronic search strategies, developed from research they have recently completed, which will be of certain interest to all librarians who do systematic review or other in-depth searching.

Readers may notice a change to our citation style with this issue. EBLIP has made the switch from MLA to APA style. We hope readers are pleased with this change. The 
editorial team felt that APA was a more common style in the social sciences, and therefore one with which authors would be more familiar, leading to fewer copyediting problems. It also removed the need to continually insert page numbers whenever the author was referring to another's work, and we like that APA puts the date of the work front and centre in the in-text citation so readers can know when the paper being referred to was published. Certainly we will go through a transition period that won't be perfect, but I hope that this change is one that is for the better.

Finally, I would like to welcome Jonathan Eldredge to the Editorial Team. Jon takes over from Scott Walter as Associate Editor for Classics. Jon is very familiar with the Classics section, as he himself has written two classic summaries in the past. We are aiming to publish at least two classics per year, and Jon would love to hear from you with suggestions of older research papers that have influenced practice, stood the test of time, and still have much to teach us. A major goal of EBLIP is to bring research closer to practitioners, and to make it useful. Classics and evidence summaries are ways in which our team continually strives to bridge this gap, and continues to inspire our minds to look at things in new ways. 